\title{
Study of number of total mortality, cardiovascular and respiratory mortality attributed to air pollutants of Tehran in 2005-2014
}

\author{
Kermani M. ${ }^{1,2}$, Dowlati M., ${ }^{3}$, Jafari A.J..,4, Roshanak Rezaei Kalantari R.R. ${ }^{1,4}$ and Sakhaei F.S. ${ }^{5}$ \\ ${ }^{1}$ Research Center for Environmental Health Technology, Iran University of Medical Sciences, Tehran, Iran. \\ ${ }^{2}$ Associate Professor of Environmental Health Engineering Department, School of Public Health, Iran University of Medical Sciences, \\ Tehran, Iran \\ ${ }^{3}$ Health Management and Economics Research Center, Iran University of Medical Sciences, Tehran, Iran \\ ${ }^{4}$ Professor of Environmental Health Engineering Department, School of Public Health, Iran University of Medical Sciences, Tehran, Iran \\ ${ }^{5} \mathrm{M} . S c$. Student of Nursing, Faculty of Nursing and Midwifery, Azad University of Medical Sciences, Tehran, Iran \\ Received: 13/09/2017, Accepted: 11/07/2018, Available online: 26/09/2018 \\ *to whom all correspondence should be addressed: e-mail: mohsendowlati.69@gmail.com \\ https://doi.org/10.30955/gni.002459
}

\section{Abstract}

Over the last few decades, the evidence on the adverse effects on the health of air pollution has been raised. Mortality is the most important health effect of ambient air pollution. We studied the relation between mortality and criteria pollutant air in Tehran, one of the highly industrialized, densely populated area and most polluted cities of the reign, during 2005-2014. For this purpose, we applied the approach proposed by the World Health Organization using the AirQ 2.2.3 model. Hourly concentrations of pollutants were taken from the Tehran environmental protection agency and Air Quality Control Company. In this model, the attributable proportion of health outcome, the annual number of excess cases of mortality for all causes were estimated. According to results, the number of total mortalities caused by exposure to $\mathrm{O}_{3}, \mathrm{NO}_{2}, \mathrm{SO}_{2}, \mathrm{PM}_{10}, \mathrm{PM}_{2.5}$ in the past decade was 8042 , 15141, 8136, 17776 and 20015 cases, respectively. The number of cumulative total mortality was 53110 cases in ten years. Furthermore, the number of cumulative cardiovascular and respiratory mortality 33887 and 8168 cases was estimated in last decade. A large number of residents of Tehran have died as a result of exposure to air pollutants; therefore, for control and management of air pollution, appropriate actions on health and the environment should be performed.

Keywords: Health, Mortality, Cardiovascular, Respiratory, Air pollution

\section{Introduction}

Nowadays, air pollution is one of the most important challenges in the field of health and the environment (Kermani et al., 2016; Motesaddi Zarandi et al., 2013; Raaee Shaktaie et al., 2017). Clean air is considered as a fundamental necessity to maintain human health (Choi, et al., 2015; Kermani et al., 2016). However, air pollution poses an important threat to health in developed and developing countries alike (Bahrami Asl et al., 2015; Contie et al., 2017). A wide range of adverse health outcomes due to short- and long-term exposure to air pollutants, at levels usually experienced by urban populations throughout the world, are established (Martuzzi et al., 2002; Kalantari et al., 2018). The numerous article on the subject includes epidemiological, clinical and toxicological studies, and research has systematically across the world documented a broad range of adverse health effects and revealed the increased mortality associated with environmental pollutants (Biggeri et al., 2001; Dockery et al., 1993; Fattore et al., 2011; Kermani et al., 2016; 2017). The WHO estimates that some $80 \%$ of premature deaths are due to ischemic heart disease and stroke caused by outdoor air pollution, $14 \%$ are due to chronic obstructive pulmonary disease or acute lower respiratory tract infections, and $6 \%$ are due to lung cancer. Children are particularly susceptible due to their fast metabolism (Danysh et al., 2015; Rodriguez-Villamizar et al., 2015). Many researchers have studied the impact of air pollution on human health and have demonstrated links between air pollution and mortality in Iran and other regions of the world. Cohen et al., (2005) used the AirQ model to determine the global burden of disease due to outdoor air pollution and reported that $\mathrm{PM}_{2.5}$ caused about 0.8 million premature deaths and 6.4 million years of life lost. Pope and Dockery (1993), summarized evaluations of health effects associated with long- and short-term exposures to ambient $\mathrm{PM}$. They reported that $\mathrm{PM}_{10}$ is associated with all-cause mortality, lung cancer (Dockery et al., 1993). Fattore et al. (2011), in Italy, was estimated as the increase in all-causes, cardiovascular and respiratory mortality, for short- and long-term exposure. Quantification of the effects attributed to air pollution particularly explains the impact of air pollutants on people and indicates the critical conditions of air quality. The AirQ model is one of the most reliable methods to quantify the effects of air pollution on the basis of "risk assessment". It is mostly an 
epidemiological and statistical model introduced by the WHO European Center for Environment and Health in 2004. This model enables the user to assess the potential effects of exposure to an identified contaminant on humans in a specific urban area and during a specific period. It is a valid and reliable tool for predicting shortterm effects of air pollutants (Jeong, 2013; WHO., 2000b). Therefore, the aim of this study was to assess the health impacts of short-term exposure to air pollutants thought quantification of the effects include of a number of total mortality and cardiovascular and respiratory mortality in Tehran city in a period of ten years (2005-1014).

\section{Materials and methods}

\section{2-1. Study Location}

Tehran is an industrialized city with a population of more than $12,500,000$ inhabitants, located in the canter of Iran with the location of $35^{\circ} 41^{\prime} \mathrm{N}-51^{\circ} 25^{\prime} \mathrm{E}$ and elevation of $1189 \mathrm{~m}$ above the sea level. The Alborz Mountains enclose the city on the northern part. The mountain range stops the flow of the humid wind to the main capital and prevents the polluted air from being carried away from the city. Thus, during winter, the lack of wind and cold air causes the polluted air to be trapped within the city. Geographical location Along with population density and a large number of motor vehicles and industrial plants Tehran, has become into one of the most polluted cities in the world (Hosseinpoor et al., 2005; Naddafi et al., 2012b).

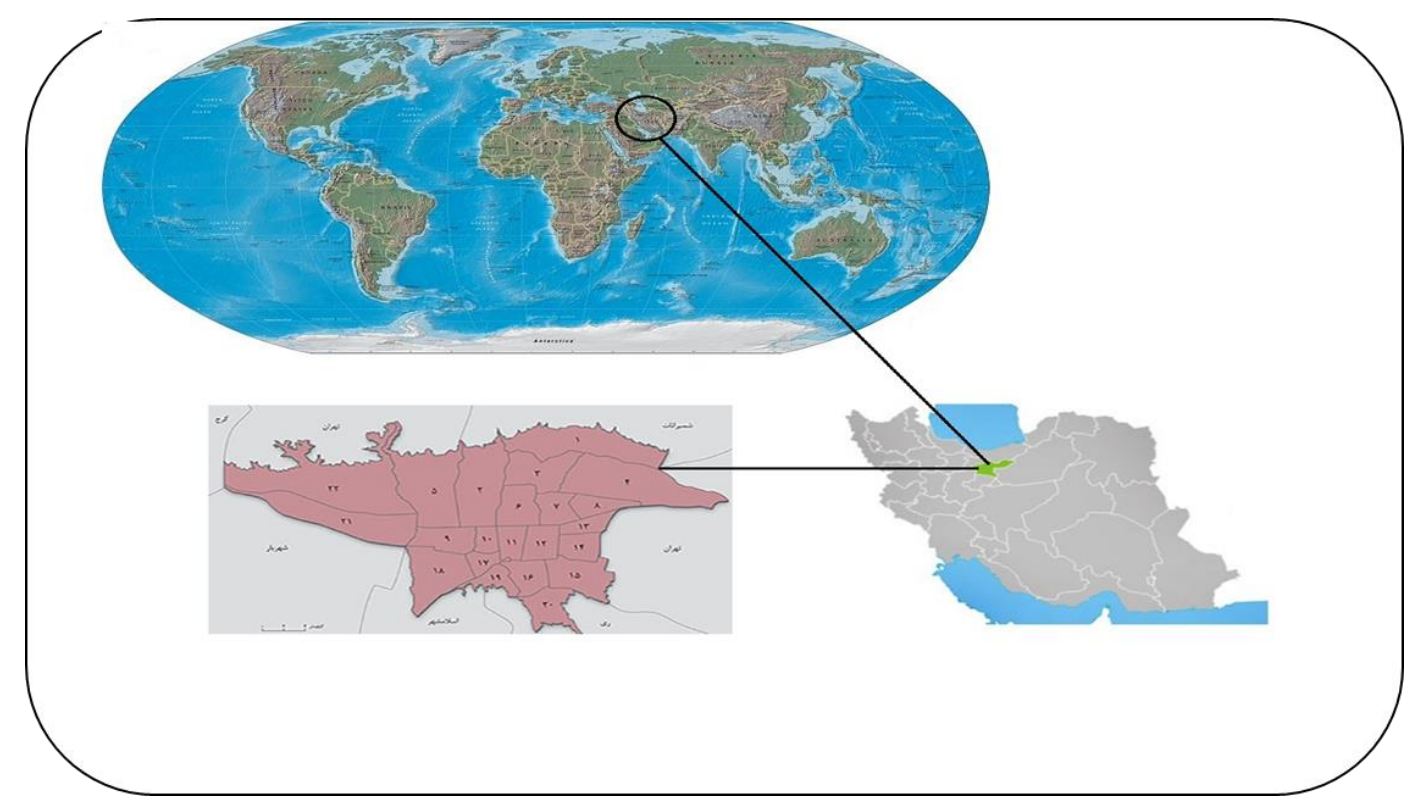

Figure 1. Location of study area (Tehran. Iran)

\section{2-2. Monitoring stations and Concentrations air pollutants}

Sampling air pollutants were a conducted by the stations all over the city Belongs to Environmental Protection Agency and the Tehran Air Quality Control Institute during 2005-2014 years. There are 40 monitoring stations and 24hour sampling stations in Tehran. The recorded raw data from stations underwent primary and secondary processes in order to determine their validity for statistical analysis based on the WHO criteria. The primary processing removed some pollutants, classified pollutants and matched them for time to measure their mean. The number of stations with valid data was identified on the basis of WHO criteria. Accordingly, the ratio of the number of valid data for two seasons (hot and cold seasons) should not be greater than 2:1. Also, there must be at least $50 \%$ valid data to achieve mean 24-hour values. Secondary processing used programming in Excel, where required statistical indicators, including annual average, hot season average, cold season average, the annual 98th percentile, annual maximum, hot season maximum and cold season maximum of the pollutants were calculated. The population reported by the Statistical Center of Iran, according to the population census was considered as the population exposed to pollution. The software determines adverse health effect, according to the pollutant mass inhaled.

\section{2-3. Relative risk (RR) and Baseline incidence (BI)}

In epidemiological studies, particularly using the AirQ model, the main health-related parameters are the relative risk (RR) and baseline incidence (BI). RR gives the increase in the probability of the adverse effect associated with a given change in the exposure levels and comes from timeseries studies where day-to-day changes in air pollutants over long periods were related to daily mortality. RR values used in the present assessment are shown in Table 1 and are mainly derived from the Air Pollution and Health: a European Approach study (APHEA), the largest multicity study related to the European population using standardized protocols for the city level data analysis. The $R R$ values used for $\mathrm{PM}_{10}$ were summary estimates derived from a quantitative meta-analysis of peer-reviewed studies focused on European investigations(H Ross Anderson et al., 2004). While for $P M_{2.5}$ the RR implemented in the software and proposed as the summary estimate in the WHO Air 
Quality Guidelines for Europe was used (WHO., 2000a). For $\mathrm{O}_{3}$ and $\mathrm{NO}_{2}$, the RR values came directly from published studies on short-term effects within the APHEA project (Gryparis et al., 2004; Samoli et al., 2006). Finally, RR values for $\mathrm{SO}_{2}$ taken from the study conducted Canadian cities (Burret and Doles, 1997). Because there is a great difference between Iran and Europe with regard to the age pyramid and the soft ware's own default data are based on

Table 1. Relative risk (RR) with confidence intervals $(95 \% \mathrm{Cl})$ and baseline incidence per 100,000 inhabitants used for Health impact assessment

\begin{tabular}{|c|c|c|c|c|c|c|}
\hline $\begin{array}{l}\text { Health end point } \\
\text { (Short-term } \\
\text { effects) }\end{array}$ & $\begin{array}{l}\text { Baseline } \\
\text { incidence } \\
\text { (BI) }\end{array}$ & & & RR $(95 \% \mathrm{Cl})$ per10 & & \\
\hline & & $\mathrm{O}_{3}$ & $\mathrm{NO}_{2}$ & $\mathrm{SO}_{2}$ & $\mathrm{PM}_{10}$ & $\mathrm{PM}_{2.5}$ \\
\hline $\begin{array}{c}\text { Total Mortality } \\
\text { (TM) }\end{array}$ & $543 / 5$ & $\begin{array}{c}1 / 003 \\
(1 / 005-1 / 002) \\
\end{array}$ & $\begin{array}{c}1 / 003 \\
(1 / 004-1 / 002) \\
\end{array}$ & $\begin{array}{c}1 / 004 \\
(1 / 0048-1 / 003)\end{array}$ & $\begin{array}{c}1 / 006 \\
(1 / 008-1 / 004)\end{array}$ & $\begin{array}{c}1 / 015 \\
(1 / 019-1 / 011)\end{array}$ \\
\hline $\begin{array}{l}\text { Cardiovascular } \\
\text { Mortality (CRM) }\end{array}$ & 231 & $\begin{array}{c}1 / 005 \\
(1 / 007-1 / 002)\end{array}$ & $\begin{array}{c}1 / 004 \\
(1 / 005-1 / 003)\end{array}$ & $\begin{array}{c}1 / 008 \\
(1 / 012-1 / 002)\end{array}$ & $\begin{array}{c}1 / 009 \\
(1 / 013-1 / 005)\end{array}$ & - \\
\hline $\begin{array}{c}\text { Respiratory } \\
\text { Mortality (RM) }\end{array}$ & $48 / 8$ & $\begin{array}{c}1 / 013 \\
(1 / 015-1 / 007)\end{array}$ & - & $\begin{array}{c}1 / 01 \\
(1 / 014-1 / 006)\end{array}$ & $\begin{array}{c}1 / 013 \\
(1 / 020-1 / 005)\end{array}$ & - \\
\hline
\end{tabular}

the European community, it cannot be used. Therefore, by reviewing the relevant studies and replacing the default values with estimates of baseline incidence and relative risk (95\% confidence intervals), we used the incidence calculated for Iran. The values of RR and BI (per 100,000 individuals) attributed to different mortality and morbidity causes are shown in Table 1.

\section{2-4. AirQ software and Health impact assessment}

In the present study, AirQ2.2.3 software, developed by the World Health Organization (WHO), was used to determine total Mortality (TM), cardiovascular Mortality (CRM) and Respiratory Mortality (RM). This model is applied to evaluate the impact of exposure to criteria atmospheric pollutants on the health of the population living in a defined period of time and location. The health impact assessment is based on the attributable proportion (AP), defined as the fraction of the health outcome in a certain population attributable to exposure to a given atmospheric pollutant, assuming a proven causal relationship between

$$
\mathrm{RR}=\frac{\text { Probability of a outcome in population exposed to pollutant }}{\text { Probability of the same outcome in population not exposed to pollutant }}
$$

The number of each case per population unit can be estimated as follows when the baseline frequency of the specific health impact in the population is known

$\mathrm{IE}=\mathrm{I} \times \mathrm{AP}$

Where IE is the incidence of exposure which is the frequency of exposure to a given concentration level and I is the baseline incidence which is the baseline frequency of the given outcome in the studied community. Knowing the population size, the number of excess cases associated

$$
\left(\frac{\text { Baseline incidencex Population }}{10^{5}}\right) \times \text { Attributable proportion=No.of excess cases }
$$

The $\mathrm{BI}$ and $\mathrm{RR}$ were used to assess the impact of $\mathrm{PM}_{10}$ on the population of Tehran as inputs of AirQ model (Table 1). The BI value was compared with the World Bank Database to assess its accuracy(WorldBank, 2012). All above formulas are based on the assumption that estimates used in this analysis have been controlled as regards to all possible confounding elements. Eventually, by entering the processed data in AirQ, the results in the form to the number of total mortality, Respiratory mortality and be calculated using Eq

$\mathrm{NE}=\mathrm{IE} \times \mathrm{N}$ the whole population, respectively. number of excess cases

\section{Results and Discussion}

exposure and health outcome and no major confounding effects in that association. The AP can be easily calculated by the following general formula (Krzyzanowski, 1997).

$A P=S U M\{[R R(c)-1] \times p(c)\} / S U M[R R(c) \times p(c)]$.

Where AP is the attributable proportion of the health impact, RR is the relative risk for a certain health impact in category " $C$ " of exposure taken from prior epidemiological studies, and $\mathrm{P}(\mathrm{c})$ is the population proportion in category " $c$ " of exposure. Relative risk (RR) is the attributable health risk associated with people who have defined exposures and can be calculated by means of as:

with the exposure for the whole population of the city can

Where $\mathrm{N}$ and NE are the population of the city and the number of excess cases attributed to given pollutant for

Baseline incidence (BI) multiplied by population size and Attributable proportion (AP) then divided in $10^{5}$ to obtain a

cardiovascular mortality due to air pollution during the recent decade, were calculated by the software.

According to Statistical Center of Iran, Tehran's population in the study period (2005-2014) was 8.098 million, 8.312 million, 8.432 million, 8.553 million, 8.676 million, 8.801 million, 8.928 million, 9.056 million, 9.187 million and 9.319 million people, respectively $(\mathrm{SCl}, 2010)$. Also, the air pollution in Tehran is mostly under the influence of 
atmospheric thermal inversion in autumn and winter season and moreover the Middle East dust storm that originating from Western Neighborhood countries(Kermani et al., 2018). In Tehran city for 20052014 year, 44033, 45218, 45915, 46554, 47149, 47832, 48574, 49250, 54168 and 50773 people have lost their lives due to natural death (all causes without accidents). We evaluated by the using of the AirQ2.2.3 model that natural mortality, cardiovascular and respiratory mortality due to $\mathrm{O}_{3}, \mathrm{NO}_{2}, \mathrm{SO}_{2}, \mathrm{PM}_{10}$ and $\mathrm{PM}_{2.5}$. Results of study such as Number and Attributable Proportion of Total Mortality, cardiovascular and respiratory mortality shown in table 2-4.

Table 2. Estimated Number of Total Mortality (TM) and Attributable Proportion (AP) (with 95\% $\mathrm{Cl}$ ) per year.

\begin{tabular}{|c|c|c|c|c|c|c|}
\hline \multirow[t]{2}{*}{ Year } & \multicolumn{6}{|c|}{ Total Mortality (TM) } \\
\hline & & $\mathrm{O}_{3}$ & $\mathrm{NO}_{2}$ & $\mathrm{SO}_{2}$ & $\mathrm{PM}_{10}$ & $\mathrm{PM}_{2.5}$ \\
\hline \multirow{4}{*}{2005} & & 522 & 1101 & 592 & 1519 & 1594 \\
\hline & Number of Cases & $(349-864)$ & $(740-14569)$ & $(446-709)$ & $(1024-2003)$ & $(1180-2000)$ \\
\hline & Attributable & 1.18 & 2.5 & 1.34 & 3.45 & 3.62 \\
\hline & Proportion & $(0.79-1.96)$ & $(1.68-3.3)$ & $(1.01-1.61)$ & $(2.32-4.55)$ & $(2.68-4.54)$ \\
\hline \multirow{4}{*}{2006} & & 547 & 1310 & 1246 & 1076 & 1343 \\
\hline & Number of Cases & $(366-905)$ & $(882-1730)$ & (941-1487) & $(723-1424)$ & $(993-1688)$ \\
\hline & Attributable & 1.21 & 2.9 & 2.75 & 2.38 & 2.97 \\
\hline & Proportion & $(0.81-2)$ & $(1.95-3.83)$ & $(2.08-3.29)$ & $(1.6-3.15)$ & $(2.19-3.73)$ \\
\hline \multirow{4}{*}{2007} & & 805 & 2116 & 1436 & 1491 & 1529 \\
\hline & Number of Cases & $(539-1326)$ & $(1432-2778)$ & $(1086-1713)$ & $(1005-1976)$ & (1131-1919) \\
\hline & Attributable & 1.75 & 4.61 & 3.13 & 3.25 & 3.33 \\
\hline & Proportion & $(1.17-2.89)$ & $(3.12-6.06)$ & $(2.37-3.73)$ & $(2.19-4.29)$ & $(2.46-4.18)$ \\
\hline \multirow{4}{*}{2008} & & 1176 & 2453 & 574 & 1675 & 2081 \\
\hline & Number of Cases & (791-19285) & $(1665-3215)$ & $(431-687)$ & $(1130-2207)$ & $(1545-2605)$ \\
\hline & Attributable & 2.53 & 5.27 & 1.23 & 3.6 & 4.47 \\
\hline & Proportion & $(1.7-4.14)$ & $(3.58-6.91)$ & $(0.92-1.47)$ & $(2.43-4.74)$ & $(3.32-5.6)$ \\
\hline \multirow{4}{*}{2009} & & 1069 & 1586 & 1351 & 1805 & 1919 \\
\hline & Number of Cases & $(718-1755)$ & $(1069-2092)$ & $(1021-1613)$ & (1219-2377) & $(1423-2405)$ \\
\hline & Attributable & 2.26 & 3.36 & 2.85 & 3.82 & 4.07 \\
\hline & Proportion & $(1.52-3.72)$ & $(2.26-4.43)$ & $(2.15-3.41)$ & $(2.58-5.04)$ & $(3.01-5.10)$ \\
\hline \multirow{4}{*}{2010} & & 905 & 1696 & 698 & 2300 & 2516 \\
\hline & Number of Cases & $(607-1490)$ & (1144-2235) & $(525-835)$ & $(1558-3019)$ & $(1872-3144)$ \\
\hline & Attributable & 1.89 & 3.54 & 1.45 & 4.81 & 5.26 \\
\hline & Proportion & $(1.27-3.11)$ & $(2.39-4.67)$ & $(1.09-1.74)$ & $(3.25-6.31)$ & $(3.91-6.57)$ \\
\hline \multirow{4}{*}{2011} & & 770 & 1175 & 942 & 2027 & 2589 \\
\hline & Number of Cases & $(516-1271)$ & (790-1555) & $(710-1126)$ & $(1370-2666)$ & $(1926-3233)$ \\
\hline & Attributable & 1.58 & 2.42 & 1.94 & 4.17 & 5.33 \\
\hline & Proportion & $(1.06-2.61)$ & $(1.62-3.2)$ & $(1.46-2.32)$ & $(2.82-5.49)$ & $(3.96-6.66)$ \\
\hline \multirow{4}{*}{2012} & & 791 & 1100 & 810 & 2117 & 2167 \\
\hline & Number of Cases & $(530-1305)$ & (783-1455) & (610-968) & $(1432-2783)$ & $(1608-2743)$ \\
\hline & Attributable & 1.6 & 2.32 & 1.64 & 4.3 & 4.4 \\
\hline & Proportion & $(1.07-2.65)$ & $(1.5-2.95)$ & $(1.23-1.96)$ & $(2.9-5.65)$ & $(2.26-5.51)$ \\
\hline \multirow{4}{*}{2013} & & 782 & 1330 & 602 & 1826 & 2373 \\
\hline & Number of Cases & (524-1290) & (894-1758) & $(452-720)$ & (1232-2405) & $(1763-2969)$ \\
\hline & Attributable & 1.56 & 2.66 & 1.2 & 3.65 & 4.75 \\
\hline & Proportion & $(1.05-2.58)$ & $(1.79-3.52)$ & $(0.9-1.44)$ & $(2.46-4.81)$ & $(3.53-5.94)$ \\
\hline \multirow{4}{*}{2014} & & 675 & 1274 & 585 & 1940 & 1904 \\
\hline & Number of Cases & $(452-1115)$ & $(856-1684)$ & $(440-7004)$ & $(1310-2554)$ & $(1410-2387)$ \\
\hline & Attributable & 1.33 & 2.51 & 1.15 & 3.83 & 3.75 \\
\hline & Proportion & $(0.89-2.2)$ & $(1.69-3.32)$ & $(0.86-1.38)$ & $(2.58-5.04)$ & $(2.78-4.71)$ \\
\hline $2005-2014$ & Number of Case & 8042 & 15141 & 8836 & 17776 & 20015 \\
\hline 2005-2014 & Number of Cases & $(5392-13249)$ & (10210-19958) & $(6662-10558)$ & $(12003-23405)$ & $(14851-25063)$ \\
\hline
\end{tabular}

Table 2 shows the association between Attributable Proportion (AP) and the cumulative number of cases total mortality caused by the exposure to atmospheric air pollutants among the people of Tehran for 2005-2014 year. Epidemiological indicators such as RR and AP are shown in this Table. In fact, these indicators were Epidemiological indices and their values depend on the selected health outcomes. In order to assess the results of the present study, the lower, upper, and central values for RR have been considered. The numbers of cumulative cases Total
Mortality (with $95 \% \mathrm{Cl}$ ) for caused by exposure to $\mathrm{O}_{3}, \mathrm{NO}_{2}$, $\mathrm{SO}_{2}, \mathrm{PM}_{10}$ and $\mathrm{PM} 2.5$ for the central RR value were 8042 , 15141, 8836, 17776 and 20015 people during the 20052014, respectively.

As seen in table 2, Most of the number of mortality is attributed to 2013 and 2014 year and related to exposure particular matter $\left(\mathrm{PM}_{10}\right.$ and $\left.\mathrm{PM}_{2.5}\right)$. Among of all pollutants, $\mathrm{PM}_{10}$ and $\mathrm{PM}_{2.5}$ have most of the number of total mortality. The high mortality in Tehran can be attributed to high 
exposures to $\mathrm{PM}_{10}$ with 17776 cases and $\mathrm{PM}_{2.5}$ with 20015 cases. This is due to increasing fuel consumption and climate and geography. For example, Middle Eastern Dust (MED) storms coming from arid areas such as Iraq and Saudi Arabia in the last years. MED storms are the main cause of dust events in the west of Iran, however, other pollution sources, including road traffic and industries, contribute to the recorded high $\mathrm{PM}_{10}$ and $\mathrm{PM}_{2.5}$ levels (Marzouni et al., 2016). Maximum exposure to $\mathrm{PM}_{10}$ was in the range $70-79 \mu \mathrm{g} / \mathrm{m}^{3}$ observed during the considered years of monitoring. Considering short-term effects, particulate matter includes $\mathrm{PM}_{10}$ and $\mathrm{PM}_{2.5}$ had the greatest health impact on the inhabitants of Tehran city, causing 37791 cases total mortality during ten years and 3779 cases in a year averagely. The Minimum number of total mortality is related to gaseous pollutants such as $\mathrm{O}_{3}$ and $\mathrm{SO}_{2}$, in the first years of study.

Table 3. Estimated Number of Cardiovascular Mortality (CRM) and Attributable Proportion (AP) (with 95\% Cl) per year.

\begin{tabular}{|c|c|c|c|c|c|}
\hline \multirow[t]{2}{*}{ Year } & \multicolumn{5}{|c|}{ Cardiovascular Mortality (CRM) } \\
\hline & & $\mathrm{O}_{3}$ & $\mathrm{NO}_{2}$ & $\mathrm{SO}_{2}$ & $\mathrm{PM}_{10}$ \\
\hline \multirow[t]{4}{*}{2005} & Number of Cases & 367 & 618 & 497 & 952 \\
\hline & & $(148-510)$ & (468-7679) & $(126-735)$ & (541-1345) \\
\hline & Attributable & 1.96 & 3.3 & 2.65 & 5.09 \\
\hline & Proportion & $(0.79-2.72)$ & $(2.5-4.10)$ & $(0.67-3.93)$ & $(2.89-7.19)$ \\
\hline \multirow[t]{4}{*}{2006} & Number of Cases & 384 & 735 & 1013 & 678 \\
\hline & & $(232-534)$ & $(556-910)$ & $(268-1506)$ & $(382-964)$ \\
\hline & Attributable & 2 & 3.83 & 5.37 & 3.53 \\
\hline & Proportion & $(1.21-2.78)$ & $(3.9-4.74)$ & $(1.39-7.84)$ & $(1.99-5.02)$ \\
\hline \multirow[t]{4}{*}{2007} & Number of Cases & 886 & 1180 & 1184 & 935 \\
\hline & & $(229-1300)$ & (899-1454) & (310-1723) & $(531-1323)$ \\
\hline & Attributable & 4.55 & 6.06 & 6.07 & 4.8 \\
\hline & Proportion & $(1.17-6.67)$ & $(4.61-7.46)$ & $(1.59-8.85)$ & $(2.72-6.79)$ \\
\hline \multirow[t]{4}{*}{2008} & Number of Cases & 819 & 1366 & 482 & 1049 \\
\hline & & $(336-1128)$ & (1042-1679) & $(122-714)$ & $(597-1480)$ \\
\hline & Attributable & 4.14 & 6.91 & 2.43 & 5.31 \\
\hline & Proportion & $(1.7-5.71)$ & $(5.27-8.49)$ & $(0.62-3.61)$ & $(3.02-7.49)$ \\
\hline \multirow[t]{4}{*}{2009} & Number of Cases & 746 & 889 & 1117 & 2132 \\
\hline & & $(305-1029)$ & (674-1099) & $(291-1630)$ & $(1448-3004)$ \\
\hline & Attributable & 3.72 & 4.43 & 5.55 & 7.04 \\
\hline & Proportion & $(1.52-5.13)$ & (3.36-5.48) & $(1.55-8.11)$ & $(4.04-9.86)$ \\
\hline \multirow{4}{*}{2010} & Number of Cases & 633 & 950 & 584 & 1432 \\
\hline & & $(258-786)$ & $(721-1174)$ & $(149-864)$ & $(821-2006)$ \\
\hline & Attributable & 3.11 & 4.67 & 2.87 & 6.13 \\
\hline & Proportion & $(1.27-4.3)$ & $(3.54-5.77)$ & $(0.73-4.25)$ & (3. 5-8.63) \\
\hline \multirow[t]{4}{*}{2011} & Number of Cases & 540 & 661 & 785 & 1266 \\
\hline & & $(219-748)$ & $(449-819)$ & $(202-1156)$ & $(723-1780)$ \\
\hline & Attributable & 2.61 & 3.2 & 3.81 & 6.31 \\
\hline & Proportion & $(1.06-3.62)$ & $(2.42-3.97)$ & $(0.98-5.6)$ & $(3.61-8.87)$ \\
\hline \multirow[t]{4}{*}{2012} & Number of Cases & 554 & 618 & 677 & 1321 \\
\hline & & $(336-768)$ & $(467-767)$ & $(173-999)$ & $(755-1856)$ \\
\hline & Attributable & 2.65 & 2.95 & 3.23 & 5.38 \\
\hline & Proportion & $(1.6-3.67)$ & $(2.23-3.67)$ & $(0.82-4.77)$ & $(3.06-7.6)$ \\
\hline \multirow[t]{4}{*}{2013} & Number of Cases & 548 & 747 & 505 & 1143 \\
\hline & & $(222-759)$ & $(565-926)$ & $(128-749)$ & $(650-1613)$ \\
\hline & Attributable & 2.58 & 3.52 & 2.38 & 5.63 \\
\hline & Proportion & $(1.05-3.58)$ & $(2.66-4.36)$ & $(0.6-3.53)$ & $(2.46-4.81)$ \\
\hline \multirow[t]{4}{*}{2014} & Number of Cases & 474 & 716 & 491 & 1213 \\
\hline & & $(192-657)$ & (541-887) & $(125-729)$ & (691-1710) \\
\hline & Attributable & 2.2 & 3.32 & 2.28 & 3.83 \\
\hline & Proportion & $(0.89-3.05)$ & $(2.51-4.12)$ & $(0.58-3.38)$ & $(3.21-7.94)$ \\
\hline $2005-2014$ & Number of Cases & 5951 & 8480 & 7335 & 12121 \\
\hline & & (2477-8309) & $(6382-10482)$ & (1894-10805) & (7139-17081) \\
\hline
\end{tabular}

Other investigators used with The AirQ software to assess the human health impact of $\mathrm{PM}_{2.5}$ (Boldo et al., 2006) or $\mathrm{PM}_{10}$ (Tominz et al., 2005). Fattore estimated the human health risk in relation to air quality in two municipalities in an industrialized area of Northern Italy, the authors found that $\mathrm{PM}_{2.5}$ had the highest health impact on the 24,000 inhabitants of the two small towns, causing an excess of total mortality of 8 out of 177 in a year; also Ozone and nitrogen dioxide each caused about three excess cases of total mortality (Fattore et al., 2011). Tominz focused on short-term effects of $\mathrm{PM}_{10}$ in Trieste (about 200,000 inhabitants), a city in northeast Italy; For $\mathrm{PM}_{10}$ concentrations above $20 \mu \mathrm{g} / \mathrm{m}^{3}, 52,28$ and 6 cases in excess, respectively, were estimated for total, 
cardiovascular and respiratory mortality (Tominz et al., 2005). In another study done in Milan $(1,308,000$ inhabitants), the central estimate of the number of excess cases attributable to PM10 was 677 for total mortality (Martuzzi et al., 2002).

Table 3 shows the association between Attributable Proportion (AP) and the cumulative number of cases Cardiovascular Mortality caused by the exposure to atmospheric air pollutants, among the people of Tehran during the 2005-2014 year.

As seen in table 3, most of the number of cardiovascular mortality is related to exposure particular matter $\left(\mathrm{PM}_{10}\right)$ and $\mathrm{NO}_{2}$. Among of all pollutants $\mathrm{PM}_{10}$ and $\mathrm{NO}_{2}$ have most of the number of cardiovascular mortality. For cardiovascular disease considered baseline incidence of 231 per $10^{5}$ people $(\mathrm{BI}=231)$, about 12121 cases can be expected annually and can be attributed to $\mathrm{PM}_{10}$ concentrations above $10 \mu \mathrm{g} / \mathrm{m}^{3}$.

Generally, the high mortality in Tehran can be attributed to high exposures to $\mathrm{PM}_{10}$ with 12121 cases and $\mathrm{NO}_{2}$ with 8480 cases. This increase can be associated with the Dust storms and use of gas fuel for heating homes and the stability of the atmosphere during the winter season.

Table 4. Estimated Number of Respiratory Mortality (RM) and Attributable Proportion (AP) (with $95 \% \mathrm{Cl}$ ) per year.

\begin{tabular}{|c|c|c|c|c|}
\hline \multirow[t]{2}{*}{ Year } & \multicolumn{4}{|c|}{ Respiratory Mortality (RM) } \\
\hline & & $\mathrm{O}_{3}$ & $\mathrm{PM}_{10}$ & $\mathrm{SO}_{2}$ \\
\hline \multirow{4}{*}{2005} & \multirow{2}{*}{ Number of Cases } & 194 & 284 & 130 \\
\hline & & $(106-222)$ & $(114-420)$ & $(79-180)$ \\
\hline & \multirow{2}{*}{ Attributable Proportion } & 4.59 & 7.19 & 3.29 \\
\hline & & $(2.72-5.66)$ & $(2.89-10.65)$ & $(2-4.55)$ \\
\hline \multirow{4}{*}{2006} & \multirow{2}{*}{ Number of Cases } & 203 & 203 & 268 \\
\hline & & $(111-232)$ & $(80-305)$ & $(165-366)$ \\
\hline & \multirow{2}{*}{ Attributable Proportion } & 5.04 & 5.02 & 6.62 \\
\hline & & $(2.78-5.77)$ & $(1.99-7.52)$ & $(4.08-9.03)$ \\
\hline \multirow{4}{*}{2007} & \multirow{2}{*}{ Number of Cases } & 295 & 279 & 308 \\
\hline & & $(164-337)$ & $(112-414)$ & $(190-418)$ \\
\hline & \multirow{2}{*}{ Attributable Proportion } & 7.19 & 6.79 & 7.48 \\
\hline & & $(4-8.2)$ & $(2.72-10.08)$ & $(4.63-10.17)$ \\
\hline \multirow{4}{*}{2008} & \multirow{2}{*}{ Number of Cases } & 422 & 312 & 126 \\
\hline & & $(238-479)$ & $(126-462)$ & $(76-175)$ \\
\hline & \multirow[b]{2}{*}{ Attributable Proportion } & 10.11 & 7.49 & 3.03 \\
\hline & & $(5.71-11.49)$ & $(3.02-11.08)$ & $(1.84-4.19)$ \\
\hline \multirow{4}{*}{2009} & \multirow{2}{*}{ Number of Cases } & 386 & 336 & 287 \\
\hline & & $(217-440)$ & $(136-496)$ & $(177-391)$ \\
\hline & \multirow{2}{*}{ Attributable Proportion } & 9.13 & 7.97 & 6.77 \\
\hline & & $(5.13-10.39)$ & $(3.21-11.71)$ & $(4.18-9.24)$ \\
\hline \multirow{4}{*}{2010} & \multirow{2}{*}{ Number of Cases } & 331 & 423 & 153 \\
\hline & & $(185-378)$ & $(173-619)$ & $(93-211)$ \\
\hline & \multirow{2}{*}{ Attributable Proportion } & 7.71 & 9.86 & 3.57 \\
\hline & & $(4.3-8.8)$ & $(4.04-14.41)$ & $(2.17-4.92)$ \\
\hline \multirow{4}{*}{2011} & \multirow[b]{2}{*}{ Number of Cases } & 284 & 376 & 205 \\
\hline & & $(258-325)$ & $(152-552)$ & $(125-282)$ \\
\hline & \multirow{2}{*}{ Attributable Proportion } & 6.53 & 8.63 & 4.71 \\
\hline & & $(3.62-7.46)$ & $(3.5-12.68)$ & $(2.88-6.48)$ \\
\hline \multirow{4}{*}{2012} & \multirow{2}{*}{ Number of Cases } & 292 & 392 & 177 \\
\hline & & $(162-333)$ & $(159-575)$ & $(108-244)$ \\
\hline & & 6.61 & 8.87 & 4.01 \\
\hline & Attributable Proportion & $(3.67-7.55)$ & $(3.61-13.03)$ & $(2.44-5.53)$ \\
\hline & & 289 & 340 & 132 \\
\hline & Number of Cases & $(160-330)$ & $(137-503)$ & $(80-183)$ \\
\hline 2013 & & 6.45 & 3.6 & 2.96 \\
\hline & Attributable Proportion & $(3.58-7.37)$ & $(3.06-11.23)$ & $(1.79-4.09)$ \\
\hline & Number of Cacec & 251 & 361 & 129 \\
\hline 20014 & Number of Cases & (139-287) & $(146-533)$ & $(78-178)$ \\
\hline 2014 & & 5.52 & 7.94 & 2.83 \\
\hline & Attributable Proportion & $(3.05-6.32)$ & $(3.21-11.72)$ & $(1.72-3.92)$ \\
\hline & & 2947 & 3306 & 1915 \\
\hline 2005-2014 & Number of Cases & $(1740-3360)$ & $(1335-4879)$ & (1171-2628) \\
\hline
\end{tabular}

On an APHEA project in Europe, the short-term impacts of air pollution, such as HACOPD, were evaluated. The RR for a $50 \mu \mathrm{g} / \mathrm{m}_{3}$ increase in the diurnal average of $\mathrm{NO}_{2}$ concentrations was $1.02 \% \quad(95 \% \quad \mathrm{Cl}: \quad 1.00 \%-1.05 \%)$
(Anderson and Leon, 1996). In another study, an increase in $\mathrm{NO}_{2}$ levels was associated with an $11 \%$ increase in daily hospitalizations for cardiorespiratory diseases (Burret and Doles, 1997). In Sao Paulo, Brazil, the atmospheric $\mathrm{NO}_{2}$ had 
a significant relationship with increased HACOPD (Gouveia, et al., Marcilio, 2006). In Bushehr, Iran, every $10 \mu \mathrm{g} / \mathrm{m}_{3}$ increase of $\mathrm{NO}_{2}$ concentrations led to an increased risk of mortality and morbidity cases of about $0.4 \%$ in the year 2011-2012 (Zallaghi et al., 2014). In Toronto, Canada, study results illustrated that there were 7.7 cases of COPD hospitalization, $40.4 \%$ of which were because of exposure to $\mathrm{NO}_{2}$ (Burret and Doles, 1997). The results of this study showed that $3.7 \%$ of the health endpoints attributed to $\mathrm{NO}_{2}$ occurred on days with pollutant levels not exceeding $40 \mu \mathrm{g} / \mathrm{m}^{3}$ and above.

Table 4 demonstrates the Attributable Proportion (AP) and the cumulative number of cases, respiratory Mortality caused by the exposure to atmospheric air pollutants among the people of Tehran during the 2005-2014 year.

Cumulative numbers of excess cases of Respiratory Mortality attributed to $\mathrm{O}_{3}, \mathrm{SO}_{2}, \mathrm{PM}_{10}$ were 2947, 19115 and 3306 persons, respectively.

As shown in table 4 the highest number of Respiratory Mortality (RM) is related to $\mathrm{PM}_{10}$ and $\mathrm{O}_{3}$ with 3306 and 2947 cases. Our findings confirmed Total mortality, Cardiovascular Mortality and Respiratory Mortality (RM) caused due to ozone exposure in ten years 8042, 5951 and 2947 cases were estimated for $\mathrm{O}_{3}$ levels above $10 \mu \mathrm{g} / \mathrm{m}^{3}$.

The high percentage of the observed mortality in this study was related to high concentrations of Tropospheric ozone and Industries and factories in Tehran, Iran.

In a study in Suwon, South Korea with a population of about $1,118,000$ people, the cumulative number of excess cases due to exposure to $\mathrm{O}_{3}$ was 43 persons(Jeong, 2013). In Tabriz, Iran with $1,500,000$ populations, the cumulative number of excluding accidental cases of 47 persons was obtained for HA-COPD in 2008-2009 (Ghozikali et al., 2016). In Shiraz, the cumulative number of excess cases attributable to $\mathrm{O}_{3}$ was estimated to be 218 and 85 persons for CM and RM, respectively (Mohammadi et al., 2016). The results of another study conducted in Ahvaz found that $3.52 \%$ (95\% Cl: $0.05-5.58 \%)$ of mortality and morbidity was associated with $\mathrm{O}_{3}$ concentrations above $10 \mu \mathrm{g} / \mathrm{m}^{3}$ (Goudarzi et al., 2013). There was an association between the increase of $\mathrm{O}_{3}$ level and a rise of HA-COPD risk in Minnesota, USA (Schwartz, 1997). In a study of $\mathrm{PM}_{10}$ and $\mathrm{O}_{3}$ impact on human health in 13 Italian cities, with about nine million inhabitants during the period 2002-2004, it was reported that on average 8220 deaths a year, excluding accidental causes, were attributable to $\mathrm{PM}_{10}$ above 20 $\mu \mathrm{g} / \mathrm{m}^{3}$. For $\mathrm{O}_{3}$ the effect was estimated at 516 extra deaths yearly. For short-term effects, exposure to $\mathrm{PM}_{10}$ above 20 $\mu \mathrm{g} / \mathrm{m} 3$ was responsible for 1372 extra deaths(Martuzzi et al., 2002). A study conducted by Naddafi proved by considering short-term effects, $\mathrm{PM}_{10}$ had the highest health impact on the 8,700,000 inhabitants of Tehran city, causing an excess of total mortality of 2194 out of 47284 in a year(Naddafi et al., 2012a). Results obtained from the studies of health impact assessment of air pollution in Tehran and various parts of the world. Particulate matter is the pollutant with the biggest health effects in all of these papers, including the present study (Curtis et al., 2006; Dockery et al., 1989; Wordley et al., 1997).

Due to a lot of charts in ten years, we preferred to show last year studied (2014) in figure 2. Figure 2 shows the results of quantifying the health endpoints of exposure to pollutants in Tehran obtained from the software. This figure illustrates diagrams based on the cumulative number of each health endpoint and the cumulative number of estimated excess cases at the lowest middle, and upper ranges $(5 \%, 50 \%$, and $95 \%)$, respectively. In the three curves of RR (associated with upper, central, and lower) in each diagram, the upper curve corresponded to a 95\% RR (overestimate), the ideal curve related to the central RR, and the lower curve corresponded to a $5 \%$ of $R R$ (underestimate).

The presence of an increasing risk of total mortality associated with an increase of exposure to pollutant concentrations in the population observed shows in figure 2.

This risk is significant considering mortality and also analyzing for criteria air pollutants. For all the pollutants, the risk seems quite negligible to lower levels of exposure $\left(\mathrm{PM}_{10}<40 \mu \mathrm{g} \mathrm{m}\right)$, while the risk continues its increasing to the highest levels of exposure.

We assessed the health effects of criteria atmospheric pollution in Tehran, Iran during 2005-2014 by using a methodology developed by the WHO.

In Tabriz, with a total population of about $10,000,000$ people, total natural mortality (non- accidental mortality) is about 50,000 people annually; and out of this number, the mortality of 5000 people can be attributed to $\mathrm{PM}_{10}$ concentrations above $10 \mu \mathrm{g} / \mathrm{m}^{3}$. Therefore, based on this model, mortality of exposure to $\mathrm{PM}_{10}$ in Tehran was approximately $4 \%$ of all mortality, that to compare with the results of other study done in Tehran (3.40\%) (Goudarzi et al., 2009).

These recent findings are in agreement with those of 20112012 study conducted in three cities of Iran. Total mortality, Cardiovascular Mortality and Respiratory Mortality (RM) caused due to exposure to sulfur dioxide in ten years 8836, 7335 and 19915 cases were estimated. Based on the results of this study, an increase of $10 \mu \mathrm{g} / \mathrm{m}^{3}$ in sulfur dioxide level was associated with an increase of 3 $\%$ in the TM, CRM and RM. Sunyer et al., (2003), in their study had shown the association of daily sulfur dioxide air pollution levels with hospital admissions for cardiovascular diseases in Europe. They demonstrated that an increase of $10 \mathrm{\mu g} / \mathrm{m}^{3}$ in sulfur dioxide levels was related to an increase of $0.7 \%$ in hospital admissions for cardiovascular diseases. Another study in Detroit, USA, Lipmann et al reported a meaningful association between sulfur dioxide and health effects on human. It was observed that an increase of 10 $\mathrm{\mu g} / \mathrm{m}^{3}$ in the sulfur dioxide was associated with an increase of $2 \%$ in hospital admissions (Lippmann et al., 2000). The high percentage of the mortality in Tehran can be related to existing Industry, manufacturing and mobile vehicles, particularly in wintertime. The impact assessment of air pollution on public health is an important topic because air 
pollution continues to be a risk factor for human health, especially in Iran where air pollutant concentrations continue to rise (Kermani et al., 2016). Local analyses of the

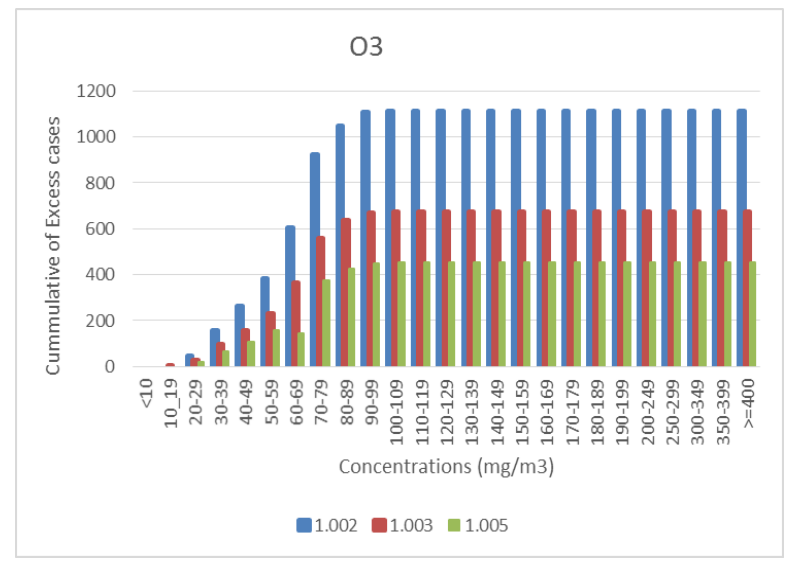

SO2

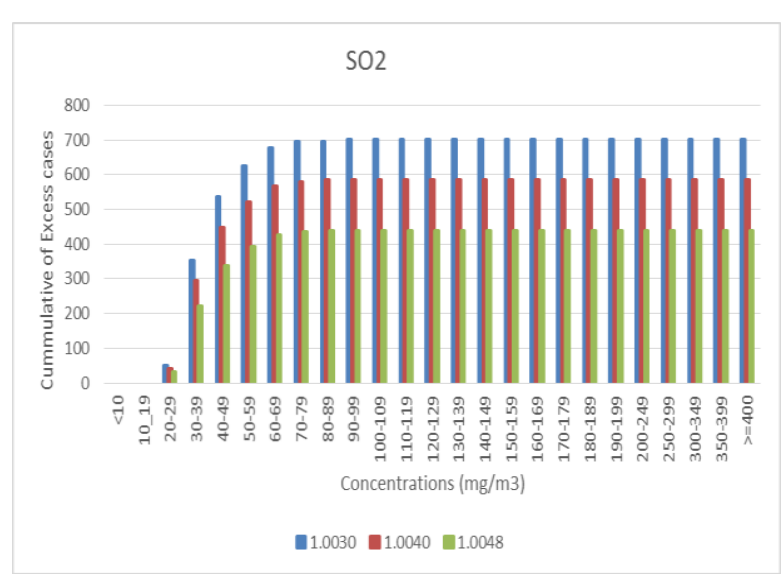

health effects of air pollution are limited, so the use of the AirQ model and similar software is necessary to provide an evaluation of the potential health effects.
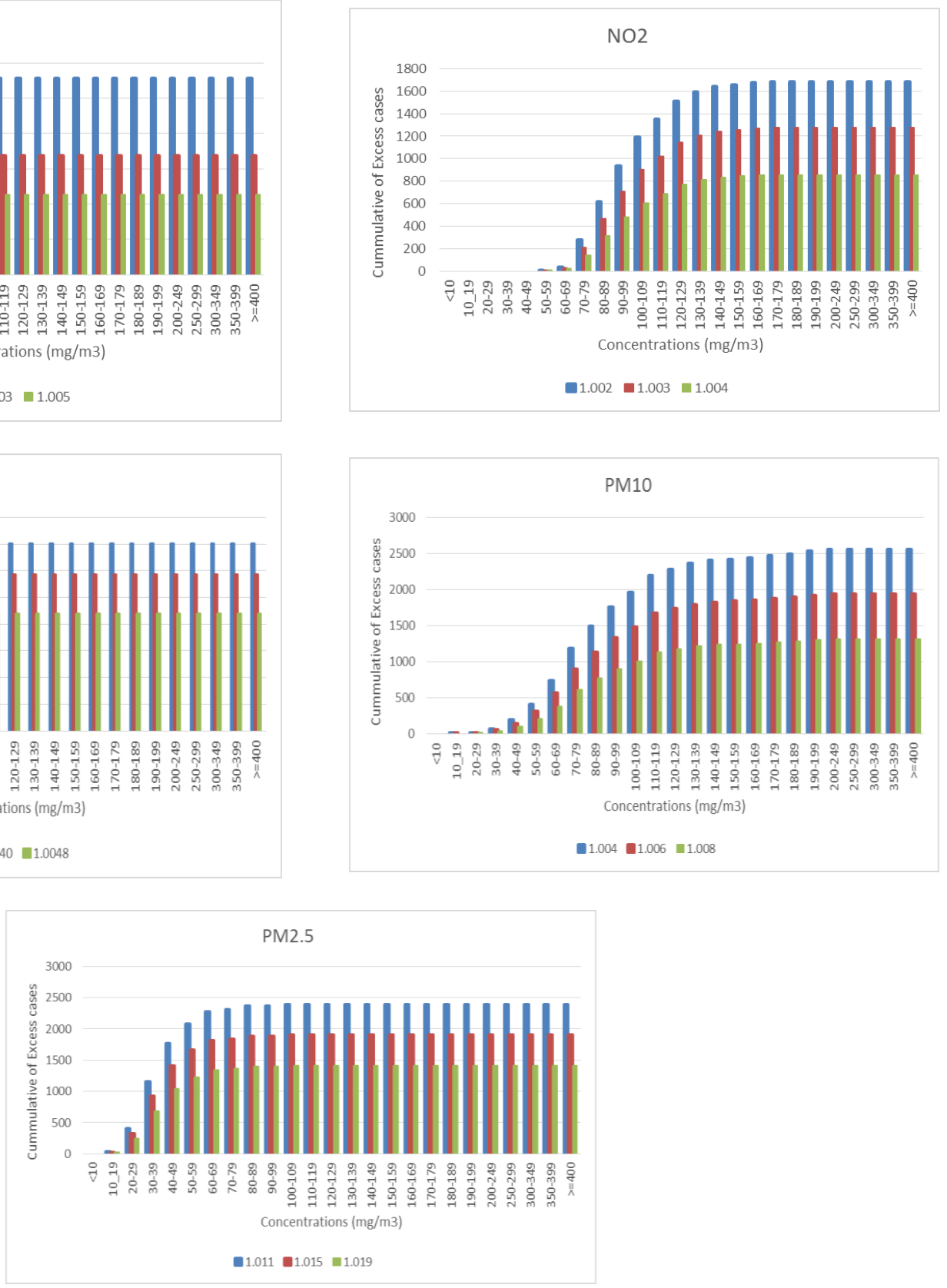

Figure 2. Relationship between cumulative number of health effects and air pollutants concentrations in 2014

\subsection{Limitations}

Our study has some limitations. One of the limitations of this approach is that the health effect centralized on individual compounds without considering the synchronous exposure to several, which is what actually happens. The health impacts of pollution are surely the outcome of interactions between various air contaminants, and between these and other compounds of natural origin. Commonly, in quantitative health impact assessments, the interactions between various pollutants are not considered as it would demand a good knowledge of the structure of toxicity of the various compounds, which is scarcely accessible. The Further limitation is because of the RR estimates derived in researches of other populations in comparison to the one under investigation.

\section{Conclusion}

In this study, has assessed the effects of criteria air pollutants on the health of Tehran residents, Iran by using the approach of WHO in a period of ten years (2005-2014). Results of this study are consistent with those of similar studies conducted in Iran and around the world according to the results of this study Air pollution in Tehran increased in recent years significantly. The highest health effects in Tehran were related particular matter. High level of air pollutants concentrations, especially particular matter, 
including PM10 and PM2.5 could increase the mortality and cardiovascular and respiratory diseases. This is due to high population and subsequently heavy traffic, Fossil fuel consumption and also dust storms with the origin of the west and south of Iran. This situation acknowledges the Measures should be taken to control release from different sources such as Factories and industries, motor vehicles to reduce the concentration of air pollutants and measures to deal with dust. Also, it's necessary that the authorities, specialist, policy makers and Citizens have been resolved to reduce air pollutants. For example, using clean energy, Public transport development, Optimization combustion process, Developing a culture of non-use of personal vehicles and Limitations People's daily activities, particularly elderly, children, and people with pre-existing heart conditions during polluted days, Additionally, strategic management of Urban development and policymaking on health and the environment, could be effective in reducing the effects of air pollution.

\section{Acknowledgment}

This work was funded by Iran University of Medical Sciences, Grant number 25455. We also thank environmental protection agency Tehran and Air Quality Control Company for providing us pollutants concentrations data. We acknowledge the critical comments from anonymous reviewers and the editor.

\section{Conflict of interest}

The authors declare that there are no conflicts of interest

\section{References}

Anderson H.R., Atkinson R.W., Peacock J., Marston L. and Konstantinou K. (2004), Meta-analysis of time-series studies and panel studies of particulate matter (PM) and ozone (O3): report of a WHO task group, World Health Organization.

Anderson H.R. and Leon A.P. (1996), Air pollution and daily mortality in London: 1987-92, BMJ, 312. doi:10.1136/bmj.312.7032.665

Bahrami Asl F., Kermani M., Aghaei M., Karimzadeh S., Salahshour Arian S., Shahsavani A. and Goudarzi G. (2015), Estimation of Diseases and Mortality Attributed to $\mathrm{NO}_{2}$ pollutant in five metropolises of Iran using AirQ model in 2011-2012, Journal of Mazandaran University of Medical Sciences, 24(121), 239249.

Biggeri A., Bellini P. and Terracini B. (2001), Meta-analysis of the Italian studies on short-term effects of air pollution, Epidemiol Prev, 25(2 Suppl), 1-71.

Boldo E., Medina S., LeTertre A., Hurley F., Mucke H.G., Ballester F., Aguilera I., Eilstein D. and Apheis Group (2006), Apheis: health impact assessment of long-term exposure to $\mathrm{PM}(2.5)$ in 23 European cities, Eur J Epidemiol, 21. doi:10.1007/s10654-006-9014-0

Burret R.T. and Doles R.E. (1997), Association between ambient carbon monoxide levels and hospitalization for congestive heart failure in the elderly in 10 Canadian cities, Epidemiology, 8. doi:10.1097/00001648-199703000-00007

Choi H., Melly S. and Spengler J. (2015), Intraurban and Longitudinal Variability of Classical Pollutants in Kraków, Poland, 2000-2010. International Journal of Environmental Research and Public Health, 12(5), 4967-4991. doi:10.3390/ijerph120504967
Cohen A.J., Ross Anderson H., Ostro B., Pandey K.D., Krzyzanowski M., Künzli N., Gutschmidt K., Pope A., Romieu I., Samet J.M. and Smith K. (2005), The global burden of disease due to outdoor air pollution, Journal of Toxicology and Environmental Health, Part A, 68(13-14), 1301-1307.

Curtis L., Rea W., Smith-Willis P., Fenyves E. and Pan Y. (2006), Adverse health effects of outdoor air pollutants, Environment International, 32(6), 815-830.

Danysh H.E., Mitchell L.E., Zhang K., Scheurer M.E. and Lupo P.J. (2015), Traffic-related air pollution and the incidence of childhood central nervous system tumors: Texas, 2001-2009, Pediatric Blood and Cancer, 62(9), 1572-1578. doi:10.1002/pbc.25549

Dockery D., Speizer F., Stram D., Ware J., Spengler J. and Ferris Jr B. (1989), Effects of inhalable particles on respiratory health of children, Am Rev Respir Dis, 139(3), 587-594.

Dockery D.W., Pope C.A. 3rd, Xu X., Spengler J.D., Ware J.H., Fay M.E., Ferris B.G. Jr and Speizer F.E. (1993), An association between air pollution and mortality in six U.S. cities, $N$ Engl J Med, 329(24), 1753-1759. doi:10.1056/nejm199312093292401

Fattore E., Paiano V., Borgini A., Tittarelli A., Bertoldi M., Crosignani P. and Fanelli R. (2011), Human health risk in relation to air quality in two municipalities in an industrialized area of Northern Italy, Environ Res, 111(8), 1321-1327. doi:10.1016/j.envres.2011.06.012

Ghozikali M.G., Heibati B., Naddafi K., Kloog I., Conti G.O., Polosa R. and Ferrante M. (2016), Evaluation of chronic obstructive pulmonary disease (COPD) attributed to atmospheric $\mathrm{O}_{3}, \mathrm{NO}_{2}$ and $\mathrm{SO}_{2}$ using Air Q Model (2011-2012 year), Environmental Research, 144, 99-105.

Goudarzi G., Zallaghi E., Neissi A., Ankali K., Saki A., Babaei A., Alavi N. and Mohammadi M. (2013), Cardiopulmonary mortalities and chronic obstructive pulmonary disease attributed to ozone air pollution, Archives of Hygiene sciences, 2(2), 62-72.

Gouveia N., Freitas C.U.D., Martins L.C. and Marcilio I.O. (2006), Respiratory and cardiovascular hospitalizations associated with air pollution in the city of São Paulo, Brazil, Cadernos de Saúde Pública, 22(12), 2669-2677.

Gryparis A., Forsberg B., Katsouyanni K., Analitis A., Touloumi G., Schwartz J., Samoli E., Medina S., Anderson H.R., Niciu E.M., Wichmann H.E., Kriz B., Kosnik M., Skorkovsky J., Vonk J.M. and Dortbudak Z. (2004), Acute effects of ozone on mortality from the "air pollution and health: a European approach" project, $A m$ J Respir Crit Care Med, 170. doi:10.1164/rccm.200403-3330C

Hosseinpoor A.R., Forouzanfar M.H., Yunesian M., Asghari F., Naieni K.H. and Farhood D. (2005), Air pollution and hospitalization due to angina pectoris in Tehran, Iran: A timeseries study, Environmental Research, 99(1), 126-131. doi:https://doi.org/10.1016/i.envres.2004.12.004

Jeong S.J. (2013), The impact of air pollution on human health in Suwon City, Asian Journal of Atmospheric Environment, 7(4), 227-233.

Kermani M., Aghaei M., Gholami M., Bahrami asl F., Karimzade S., Falah S. and Dolati M. (2016), Estimation of Mortality Attributed to PM2.5 and CO Exposure in eight industrialized cities of Iran during 2011, Iran Occupational Health Journal, 13(4), 49-61.

Kermani M., Dowlati M., Jafari A.J. and Kalantari R.R. (2016), Health risks attributed to particulate matter of 2.5 microns or 
less in Tehran air 2005-2014, Journal of Kermanshah University of Medical Sciences, 20(3), 99-105.

Kermani M., Dowlati M., Jonidi Jafari A., Rezaei Kalantari R. and Sadat Sakhaei F. (2016), Effect of Air Pollution on the Emergency Admissions of Cardiovascular and Respiratory Patients, Using the Air Quality Model: A Study in Tehran, 2005-2014. Health in Emergencies and Disasters Quarterly, 1(3), 137-146. doi:10.15412/j.hdq.09010304

Kermani M., Dowlati M., Jonidi Jafari A. and Rezaei Kalantari R. (2016), Estimation of Mortality, Acute Myocardial Infarction and Chronic Obstructive Pulmonary Disease due to Exposure to $\mathrm{O}_{3}, \mathrm{NO}_{2}$, and $\mathrm{SO}_{2}$ in Ambient Air in Tehran, Journal of Mazandaran University of Medical Sciences, 26(138), 96-107.

Kermani M., Dowlati M., Jonidi Jafari A. and Rezaei Kalantari R. (2017), Health impact caused by exposure to particulate matter in the air of Tehran in the past decade, Tehran University Medical Journal, 74(12), 885-892.

Kermani M., Dowlati M., Jonidi Jafari A. and Rezaei Kalantari R. (2018), Number of mortality, chronic obstructive pulmonary disease and acute myocardial infarction due to exposure to sulfur dioxide in Tehran, during 2005-2014, Koomesh Journal, 20(1), 34-42.

Kermani M., Fallah Jokandan S., Aghaei M., Bahrami Asl F., Karimzadeh S. and Dowlati M. (2016), Estimation of the Number of Excess Hospitalizations Attributed to Sulfur Dioxide in Six Major Cities of Iran, Health Scope, 5(4), e38736. doi:10.17795/jhealthscope-38736

Krzyzanowski M. (1997), Methods for assessing the extent of exposure and effects of air pollution, Occup Environ Med, 54. doi:10.1136/oem.54.3.145

Lippmann M., Ito K., Nadas A. and Burnett R. (2000), Association of particulate matter components with daily mortality and morbidity in urban populations, Res Rep Health Eff Inst, 95, 572, discussion 73-82.

Martuzzi M., Galassi C., Ostro B., Forastiere F. and Bertollini R. (2002), Health impact assessment of air pollution in the eight major Italian cities WHO, World Health Organization Europe.

Marzouni M.B., Alizadeh T., Banafsheh M.R., Khorshiddoust A.M., Ghozikali M.G., Akbaripoor S., Sharifi R. and Goudarzi G. (2016), A comparison of health impacts assessment for PM 10 during two successive years in the ambient air of Kermanshah, Iran, Atmospheric Pollution Research, 7(5), 768-774.

Mohammadi A., Azhdarpoor A., Shahsavani A. and Tabatabaee H. (2016), Investigating the health effects of exposure to criteria pollutants using AirQ2. 2.3 in Shiraz, Iran, Aerosol and Air Quality Research, 16(4), 1035-1043.

Motesaddi Zarandi S., Raei Shaktaie H., Yazdani Cheratee J., Hosseinzade F. and Dowlati M. (2013), Evaluation of PM2.5 Concentration and Determinant Parameters on its Distribution in Tehran's Metro System in 2012, Journal of Mazandaran University of Medical Sciences, 22(2), 36-46.

Naddafi K., Hassanvand M.S., Yunesian M., Momeniha F., Nabizadeh R., Faridi S. and Gholampour A. (2012a), Health impact assessment of air pollution in megacity of Tehran, Iran, Iranian Journal of Environmental Health Science and Engineering, 9(1), 28.

Naddafi K., Hassanvand M.S., Yunesian M., Momeniha F., Nabizadeh R., Faridi S. and Gholampour A. (2012b), Health impact assessment of air pollution in megacity of Tehran, Iran, Iranian Journal of Environmental Health Science and Engineering, 9(1), 1-7. doi:10.1186/1735-2746-9-28
Oliveri Conti G., Heibati B., Kloog I., Fiore M. and Ferrante M. (2017), A review of AirQ Models and their applications for forecasting the air pollution health outcomes, Environmental Science and Pollution Research International, 24(7), 64266445. doi:10.1007/s11356-016-8180-1

Raaee Shaktaie H., Motesaddi Zarandi S., Zazouli M.A., Yazdani Cheratee J., Hosseinzade F. and Dowlati M. (2017), Study Concentration of particulate matter with aerodynamic diameter less than 10 micron (PM10) in the metro underground transport system of Tehran, Journal of Mazandaran University of Medical Sciences, 27(151), 166179.

Rezaei Kalantari R., Kermani M., Dowlati M. and Jonidi Jafari A. (2018), Number of mortality, chronic obstructive pulmonary disease and acute myocardial infarction due to exposure to sulfur dioxide in Tehran, during 2005-2014, Koomesh Journal, 20(1), 34-42.

Rodriguez-Villamizar L.A., Magico A., Osornio-Vargas A. and Rowe B.H. (2015), The effects of outdoor air pollution on the respiratory health of Canadian children: A systematic review of epidemiological studies, Canadian Respiratory Journal, 22(5), 282-292.

Samoli E., Aga E., Touloumi G., Nisiotis K., Forsberg B., Lefranc A., Pekkanen J., Wojtyniak B., Schindler C., Niciu E., Brunstein R., Dodic Fikfak M., Schwartz J., Katsouyanni K. (2006), Shortterm effects of nitrogen dioxide on mortality: an analysis within the APHEA project, European Respiratory Journal, 27(6), 1129-1138.

Schwartz J. (1997), Air pollution and hospital admissions for cardiovascular disease in Tucson, Epidemiology, 371-377.

SCI. (2010). Statistical Center of Iran, IRAN STATISTICAL YEARBOOK. Retrieved from

Sunyer J., Ballester F., Tertre A.L., Atkinson R., Ayres J.G., Forastiere F., Forsberg B., Vonk J.M., Bisanti L., Tenías J.M., Medina S., Schwartz J. and Katsouyanni K., (2003), The association of daily sulfur dioxide air pollution levels with hospital admissions for cardiovascular diseases in Europe (The Aphea-II study), European Heart Journal, 24(8), 752-760.

Tominz R., Mazzoleni B. and Daris F. (2005), Estimate of potential health benefits of the reduction of air pollution with PM10 in Trieste, Italy, Epidemiologia e Prevenzione, 29(3-4), 149-155.

Tominz R., Mazzoleni B. and Daris F. (2005), Estimate of potential health benefits of the reduction of air pollution with PM10 in Trieste, Italy, Epidemiol Prev, 29.

WHO. (2000a). Air Quality Guidelines for Europe, seconded. Retrieved from WHO Regional Publications:

WHO. (2000b). Quantification of the Health Effects of Exposure to Air Pollution. Retrieved from Bilthoven, Netherlands.:

Wordley J., Walters S. and Ayres J.G. (1997), Short term variations in hospital admissions and mortality and particulate air pollution, Occupational and Environmental Medicine, 54(2), 108-116.

WorldBank. (2012). World Bank Database. World Bank. http://data.worldbank.org/ indicator. Retrieved from

Zallaghi E., Goudarzi G., Haddad M., Moosavian S. and Mohammadi M. (2014), Assessing the effects of nitrogen dioxide in urban air on health of west and southwest cities of Iran, Jundishapur J Health Sci, 6(4), e23469. 